\title{
Nine Year Median Follow Up of Mid-Urethral Slings and Autologous Sling, Single Center Experience
}

\section{Mohamed Elkhamesy, Ahmed A Selim and Bassem S Wadie*}

Urology and Nephrology Center, Mansoura University, Egypt

*Corresponding author: Bassem S Wadie, MSc, MD, Professor of urology, Head, voiding dysfunction, female urology \& Reconstruction, Urology and Nephrology Center, Mansoura University, Egypt, Tel: 20-50-2202222; Email: Bassem_Wadie@mans.edu.eg

\section{Research Article}

Volume 5 Issue 2

Received Date: April 08, 2020

Published Date: May 04, 2020

DOI: $10.23880 /$ oajun-16000178

\section{Abstract}

Objective: Evaluation of the subjective and objective cure rates as well as adverse events of 3 major procedures used for treatment of SUI. We also compared them in attempt to explore their long-term efficacy and safety

Materials and Methods: All baseline demographic data as well as clinical data including stress and pad tests were collected. Urodynamics at baseline and at last follow up were reported together with UDSi-6 and IIQ-7 symptoms scores of all women included. SPSS was used for statistical analysis.

Results: Study included 65 women; 32 underwent PVS while 19 TVT and 14 TOT with a mean age was $46.55 \pm 7.07$. All were followed to a minimum of 5 years (Median: 9 years). 39 had isolated stress incontinence while 26 had MUI. 30 had grade I POP and 5 patients had grade II POP. 40 women (61.5\%) underwent sling only, while 38.5\% underwent concomitant surgery for POP. At last follow up, 58 patients had no POP while 7 patients had. Stress test was negative in 55 patients while ten patients had positive stress test. Quality of life at last follow up showed no significant difference among treatment groups

Conclusion: Synthetic MUS were comparable to PVS at long term follow up. All slings maintained a reasonable objective cure rate with time while no new adverse events develop after 5 years.

Keywords: Sling; MUS; Long-term; Outcome

Abbreviations: ALPP: Abdominal Leak Point Pressure; MUS: Mid Urethral Sling; POP: Pelvic Organ Prolapse; PVR: Post Voiding Residual Urine; PVS: Pubovaginal Sling; USI 6: Urogenital Distress Inventory 6; IIQ 7: Incontinence Impact Questionnaire 7; SUI: Stress Urinary Incontinence.

\section{Introduction}

MUS are the mainstay of surgical treatment of women with SUI. We first reported the comparative efficacy of TVT as compared to PVS in the first reported RCT on the subject [1]. Since then, tremendous amount of publications evolved on the long term efficacy of either PVS or synthetic MUS [2,3]. Since 2011, after the FDA has issued it public notification on the use of mesh in correction of POP, a trend of decline in the use of mesh in correction of POP was first reported [4], then a decline in the use of synthetic MUS was also reported. Rac, et al. [5] have also noted that PVS have witnessed significant increase in its application when compared to total SUI intervention, from $21 \%$ of all SUI surgeries in 2007 to $30 \%$ in $2013(\mathrm{P}<0.0001)$. MUS showed similar satisfactory result at medium and long term follow up. Objective cure rates were similar while TOT was associated with a lower subjective cure rate than TVT in a systematic review [6]. PVS was also attended with high cure rate. The cure/improved rate of PVS was $97 \%$ in 44 women with SUI at a median of 3 year follow up [7].

In this retrospective analysis, we evaluated women who underwent MUS or PVS over the past 14 years. We 


\section{Open Access Journal of Urology \& Nephrology}

examined the subjective and objective cure rates as well as adverse events developing during the observation period. We compared the 3 types of procedures to one another in attempt to explore their long-term efficacy and safety.

\section{Patients and Methods}

This is a retrospective study that included women who underwent mid-urethral sling (MUS) or PVS, during the period of 2001 to 2015 with a minimum follow up of five years. Patients were phone called and asked to attend an outpatient clinic visit. Informed consent was obtained from all patients before their enrollment. The study design and protocol were approved by local committee of the urology department at UNC.

\section{Preoperative evaluation}

We reviewed history, including gynecological and surgical past history. Patients were asked to fill in Arabic versions of IIQ-7, UDI-6 for evaluation of bothersome impact of stress incontinence in the last follow up visit. This questionnaire was introduced in Arabic validated form few years ago so preoperative results were not available for this analysis [8].

\section{Physical examination}

Patients underwent physical examination including stress test. The degree of pelvic organ prolapse (POP) was assessed and graded according to Baden and Walker [9]. Laboratory investigations included urine analysis with or without urine culture, serum creatinine, CBC and liver functions tests.

\section{Urodynamic testing}

Urodynamic testing was performed in all patients at baseline and 2 years afterwards. In those who experienced failure of the procedure and in patients in whom post voiding residual was more than $100 \mathrm{ml}$, urodynamics was requested at last follow up visit

\section{Follow Up Schedule and Assessment of Outcome}

Patients were assessed at the follow up visit, at which per vaginum examination, stress test, pad test, post-void residual urine (PVR) and symptom scores were recorded (a physician administered score) at this visit.

\section{Stress Test}

Stress test was performed by asking the patient to lie down, flexing her hips and thighs while the bladder is halffull and then to cough. A positive cough stress test, in which leakage is observed at the moment of the cough, is essential to confirm the diagnosis. One hour Pad test where the patient wears a pre-weighed pad, drinks $500 \mathrm{ml}$ of water and rests for 15 minutes. She then performs 30 minutes of moderate exercise, such as stair climbing and walking. The remaining 15 minutes are spent performing more provocative exercises, including coughing vigorously, bending over, hand washing and running. At the end of one hour, the pad is removed and re-weighed. Increase in pad weight more than 2 grams is considered positive. This is not identical to the recommendation of the ICS, where an increase of $1.4 \mathrm{gm}$ or more in 1-hour pad test was considered positive [10]. The explanation for this discrepancy arises from the fact that all our patients were obese, with 33.3 as an overall mean BMI. This together with more perspiration resulting from local hot climate would make $1.4 \mathrm{gm}$ cut-off value rather unrealistic [11]. The primary outcome measure was correction of SUI as measured by stress test and pad test. Secondary outcome measures were evaluated using urogenital distress inventory (UDI-6), incontinence impact questionnaire (IIQ-7), as well as long term adverse events.

\section{Results}

Sixty five women were included, 32 patients underwent PVS while 19 patients had TVT and 14 TOT with a mean age was $46.55 \pm 7.07$. All were followed to a minimum of 5 years. Median follow up was 9 years (range 5-15).

\begin{tabular}{|c|c|c|c|c|}
\hline & PVS (n= 32) & TVT (n=19) & TOT (n=14) & \multirow{2}{*}{ P value * } \\
\cline { 2 - 4 } & mean \pm (SD) & mean \pm (SD) & mean \pm (SD) & 0.5557 \\
\hline Age & $46.50 \pm(6.99)$ & $47.31 \pm(6.82)$ & $45.64 \pm(7.45)$ & 0.556 \\
\hline Gravidity & $3.63 \pm(1.66)$ & $3.17 \pm(1.09)$ & $3.43 \pm(1.34)$ & 0.874 \\
\hline Parity & $3.31 \pm(1.34)$ & $3.17 \pm(1.09)$ & $3.14 \pm(1.16)$ & 0.674 \\
\hline BMI & $34.70 \pm(10.47)$ & $31.80 \pm(3.39)$ & $33.44 \pm(4.76)$ & \\
\hline
\end{tabular}

*P value is calculated using ANNOVA test.

Table 1: Demographic Data of Patients in the Study. 
Table 1 shows demographic data. Among our patients, 39 had isolated stress incontinence while 26 complained of mixed incontinence. Of the 65 patients, 31 patients were not complaining of POP, 30 had grade I POP and 5 patients had grade II POP. Ten patients (15.4\%) had history of surgical correction of pelvic organ prolapse, 12 had other pelvic surgeries (18.5\%) and 22 (33.8\%) had irrelevant surgeries not related to the pelvis. Forty out of sixty five patients (61.5\%) underwent sling only, while the remaining twenty five patients $(38.5 \%)$ underwent concomitant surgery for POP. 19 underwent anterior colporrhaphy, 4 posterior colporrhaphy and 2 underwent combined anterior and posterior colporrhaphy. Table 2 shows the distribution of POP repair among study group. At last follow up visit, 58 patients were having normal local examination while 7 patients were complaining of prolapse $(\mathrm{P}=0.88), 4$ of them were de-novo, while 3 had previous concomitant anterior POP repair. Table 3 demonstrates the result of vaginal examination at last follow up (recall) visit.

\begin{tabular}{|c|c|c|c|c|c|}
\hline \multirow{2}{*}{ POP } & \multicolumn{5}{|c|}{ Sling type } \\
\cline { 2 - 6 } & PVS & TVT & TOT & 31 & $47.70 \%$ \\
\hline No. & 10 & 13 & 8 & 27 & $41.60 \%$ \\
\hline grade I & 18 & 4 & 5 & 7 & $10.70 \%$ \\
\hline grade II & 4 & 2 & 1 & 65 & $100 \%$ \\
\hline Total & 32 & 19 & 14 & \multicolumn{2}{c|}{ Total } \\
\hline
\end{tabular}

Table 2: Distribution of Anterior POP among Treatment Groups before Surgery.

\begin{tabular}{|c|c|c|c|c|c|}
\hline \multirow{2}{*}{ Local Examination } & \multicolumn{3}{|c|}{ Sling Type } \\
\cline { 2 - 6 } & PVS & TVT & TOT & 57 & $87.70 \%$ \\
\hline Normal & 29 & 16 & 12 & 8 & $11.30 \%$ \\
\hline Prolapse & 3 & 3 & 2 & 65 & $100 \%$ \\
\hline Total & 32 & 19 & 14 & \multicolumn{2}{c|}{ Total } \\
\hline
\end{tabular}

Table 3: Vaginal Examination Findings in Patients at Last Follow Up.

At last follow up, stress test was negative in 55 patients while ten patients had positive stress test. Difference between the three groups was insignificant regarding those with +ve stress test ( $\mathrm{p}=0.8$, using t test). Breaking up patients into 2 groups according to pad weight revealed that 48 patients had less than $2 \mathrm{Gm}$-increase ( 0 to less than 2 ) and 17 patients pad weight were more than $2 \mathrm{Gm}$. The difference between different types of MUS was not statistically significant $(\mathrm{P}=0.975)$, using ANOVA. Table 4 shows the distribution of stress test and positive pad test among treatment groups.
Table 5 shows urodynamic data of all patients at baseline. Two-year follow-up Urodynamic data is demonstrated in Table 6. No statistically significant difference between groups was noted. Quality of life at last follow up among treatment groups is displayed in Table 7. Fifty eight women had normal microscopic urine examination, while 8 patients had pus cell count more than 5/HPF. No long term adverse events were noticed from 5 years onwards, as reported by patients at last follow-up.

\begin{tabular}{|c|c|c|c|c|c|}
\hline \multirow{2}{*}{ Stress test } & \multicolumn{5}{|c|}{ Sling type } \\
\cline { 2 - 6 } & PVS & TVT & TOT & 55 & $84.60 \%$ \\
\hline -VE & 27 & 16 & 12 & 10 & $15.40 \%$ \\
\hline +VE & 5 & 3 & 2 & 65 & $100 \%$ \\
\hline Total & 32 & 19 & 14 & 48 & $73.80 \%$ \\
\hline Negative (<2 gm) & 24 & 14 & 10 & 17 & $26.20 \%$ \\
\hline Positive (> 2 gm) & 8 & 5 & 4 & 65 & $100 \%$ \\
\hline Total & 32 & 19 & 14 & Pad test \\
\hline
\end{tabular}

Table 4: Stress and Pad tests of Patients at Last Follow Up. 


\section{Open Access Journal of Urology \& Nephrology}

\begin{tabular}{|c|c|c|c|c|}
\hline \multirow{2}{*}{ N:65 } & PVS (n=32) & TVT(n=19) & T0T (n=14) & \\
\cline { 2 - 5 } & mean \pm (SD) & mean \pm (SD) & mean \pm (SD) & P Value* $^{*}$ \\
\hline PVR & $14.33 \pm(22.2)$ & $52.42 \pm(21.5)$ & $56.66 \pm(49.0)$ & 0.553 \\
\hline Abd. LPP & $82.6 \pm(28.04)$ & $80.6 \pm(28.44)$ & $94.3 \pm(29.7)$ & 0.878 \\
\hline Capacity & $396.44 \pm(116.3)$ & $344.4 \pm(123.7)$ & $408.5 \pm(163.7)$ & 0.253 \\
\hline Qmax & $13.9 \pm(7.4)$ & $17.7 \pm(8.5)$ & $13.3 \pm(6.4)$ & 0.953 \\
\hline Voided volume & $316.5 \pm(75.9)$ & $247.0 \pm(110.2)$ & $324.1 \pm(144)$ & 0.331 \\
\hline P det Q max & $20.1 \pm 11.4$ & $29.9 \pm 24.1$ & $27.66 \pm 17.6$ & 0.406 \\
\hline
\end{tabular}

${ }^{*}$ P value is calculated using ANOVA test.

Table 5: Urodynamic Variables at Baseline.

\begin{tabular}{|c|c|c|c|c|}
\hline \multirow{2}{*}{$N=60$} & PVS & TVT & TOT & \\
\hline & mean $\pm(S D)$ & mean $\pm(S D)$ & mean $\pm(S D)$ & P Value * \\
\hline PVR & $15.0 \pm(7.9)$ & $17.7 \pm(5.58)$ & $11.1 \pm(4.77)$ & 0.35 \\
\hline Capacity & $337.6(102.5)$ & $340.44(116.8)$ & $375.15 \pm(78)$ & 0.331 \\
\hline Qmax & $18.5 \pm(8.35)$ & $18 \pm(11.82)$ & $18.6 \pm(7017)$ & 0.652 \\
\hline Voided volume & $221.6 \pm(93.63)$ & $220.7 \pm(95.41)$ & $298 \pm(95.64)$ & 0.876 \\
\hline$P \operatorname{det} Q \max$ & $22.8 \pm(6.7)$ & $19.2 \pm(8.2)$ & $17 \pm(7.2)$ & 0.08 \\
\hline
\end{tabular}

*Significance testing using ANOVA.

Table 6: Urodynamic Variables at Interim Follow-Up.

\begin{tabular}{|c|c|c|c|c|}
\hline & PVS & TVT & TOT & \\
\cline { 2 - 5 } & mean \pm (SD) & mean \pm (SD) & mean \pm (SD) & P Value* $^{*}$ \\
\hline UDI-6 & $44.9 \pm(15)$ & $37.8 \pm(13)$ & $43.9 \pm(14)$ & 0.294 \\
\hline IIQ-7 & $42.9 \pm(18)$ & $33.5 \pm(15)$ & $37.6 \pm(18)$ & 0.157 \\
\hline
\end{tabular}

*P value was calculated using ANOVA.

Table 7: Quality of Life among Patients at Last Follow- Up.

\section{Discussion}

Approximately 200,000 SUI surgeries are performed annually in the United States, increasing by $27 \%$ from 2000 to 2009. Most of this increase is attributed to sling procedures [12]. Mean age of our patients was 46.55 years. Our patients seem to be younger than those reported by Schauer, et al. [2] where they presented 10-year follow up of 139 patients with a mean age of 63 years. Similarly, a large Danish study involving 8671 patients found that mean age was 56.1 years [13]. They were studying the re-operation rate at 5-year where the cumulative incidence of reoperation after any surgical treatment for urinary incontinence was $10 \%$. The lowest rate of reoperation was observed among women having pubovaginal slings (6\%), retropubic midurethral tape $(6 \%)$ and Burch colposuspension (6\%) followed by transobturator tape (9\%). In a Cox proportional hazard model, the transobturator tape carried a 2-fold higher risk of reoperation (HR, 2.1; 95\% CI, 1.5-2.9). In our cohort, 52.3\% had POP, ranging from grade 1 to 3 and some had anterior POP (18 cases) while 7 had posterior prolapse. The prevalence of urinary incontinence varies from $17-45 \%$ among adult women [14]. Similarly, 50\% of parous women have POP [15]. The prevalence of POP among women with SUI is somewhere between $40 \%$ to $53.4 \%$ [16,17]. Twenty five of our patients underwent concomitant correction of POP. The association of TVT-O with other procedures was studied by Cho MK, et al. [18] on 272 women having either TVT-0 only (122 patients) or TVT-0 and other procedure (150). The success rate was $89.3 \%$ in the TVT-O-only group vs. $93.3 \%$ in the TVT-O with concomitant gynecological surgery group $(\mathrm{p}=0.729)$.

Incontinence recurs in $8 \%$ of women after 10 -year follow up of TVT-O according to Serati, et al. [19]. In TOMUS trial [20], 1- year objective failure rates of $19.2 \%$ and $22.3 \%$ were reported for retropubic and transobturator MUS respectively. Objective success was defined as negative stress test, 24-hour pad test and no re-treatment for stress- 
type incontinence. Based on stress test, overall success rate was $84.6 \%$, while it was $73.8 \%$ based on 1 hour pad test. Price and Noblett [21] found that cough stress test is more reliable than the pad test for documentation of stress urinary incontinence. They founded their conclusion on the agreement between urodynamic testing and each of stress test and 24-hour pad test. Stress test showed 89\% agreement while pad test exhibited only $60 \%$. Three types of sling in our study did not show significant differences regarding success rate or HRQOL. Differences between the groups regarding PVR, bladder capacity, maximum flow rate and detrusor pressure at maximum flow as well as UDI and IIQ scores were statistically insignificant. However, detrusor pressure at maximum flow tended to be higher than both TVT and TOT (22.8 vs. 19.2 and $17 \mathrm{~cm}_{2} \mathrm{O}$ respectively). The difference did not amount to significance $(\mathrm{p}=0.08)$. Success rates at median follow up were comparable. Based on stress test, $84.4 \%, 84.2 \%$ and $85.7 \%$ success rates were noted for PVS, TVT and TOT respectively. Based on pad test, rates were lower at $75 \%, 73.7 \%$ and $73.8 \%$ respectively. Jeon, et al. [22] have reported cure rates for the 3 types of sling in women with ISD with significantly poorer outcome regarding TOT $(87.25 \%, 86.94 \%$, and $34.89 \%$, respectively; $\mathrm{P}<.0001$ ) However, more recently, Ulrich, et al. [23] have published on 10-year of follow up of 112 women with TOT. They reported subjective and objective cure rates at 10 -year to be $69 \%$ and $64 \%$ respectively. We attempted to elucidate predictors of success among our patients. Univariate analysis was performed involving BMI, parity, abd. LPP, the presence of DO, sling type and the presence of concomitant surgery (Table 8). None of these variables proved significantly affecting the outcome. In one large volume study based of SISTER, Richter, et al. [24] found that only greater baseline urge incontinence symptoms, more advanced prolapse, and menopausal not on hormone replacement therapy are the only failure risk factors in women who underwent Burch or PVS alike. Our sample size was a significant shortcoming that would hinder conducting such analysis.

\begin{tabular}{|c|c|c|c|}
\hline & Success & Failure & P value \\
\hline $\mathrm{BMI}<30$ & $63.20 \%$ & $36.80 \%$ & \multirow{2}{*}{$0.39 *$} \\
\hline$>30$ & $73.90 \%$ & $26.10 \%$ & \\
\hline Parity (1-7) & $70.80 \%$ & $29.20 \%$ & $0.71^{*}$ \\
\hline Abd. LPP $\left(30-158 \mathrm{~cm} \mathrm{H}_{2} \mathrm{O}\right)$ & $70.30 \%$ & $29.70 \%$ & $0.52 *$ \\
\hline \multicolumn{4}{|c|}{ Detrusor Overactivity } \\
\hline Present & $57.10 \%$ & $42.90 \%$ & $0.34^{* *}$ \\
\hline Absent & $72 \%$ & $28 \%$ & \\
\hline \multicolumn{4}{|c|}{ Sling Type } \\
\hline PVS & $71.90 \%$ & $28.10 \%$ & \multirow{3}{*}{$0.82^{*}$} \\
\hline TVT & $73.70 \%$ & $26.30 \%$ & \\
\hline TOT & $64.30 \%$ & $35.70 \%$ & \\
\hline \multicolumn{4}{|c|}{ Concomitant surgery $\phi$} \\
\hline No & $70 \%$ & $30 \%$ & 033* \\
\hline Yes Anterior & $70 \%$ & $30 \%$ & \\
\hline Posterior & $100 \%$ & $100 \%$ & \\
\hline Combined & $0 \%$ & $0 \%$ & \\
\hline
\end{tabular}

*Using Pearson Chi-square

** Using Fisher's exact test

Ф Surgery for POP

Table 8: Univariate Analysis to Assess Predictor of Success.

Our study is long term and involved a comprehensive array of subjective and objective outcome measures that give a reasonable insight for the long term outcome of most commonly used types of MUS. Sample size and incomplete urodynamic data are notable deficiency.

\section{References}

1. Wadie BS, Edwan A, Nabeeh AM (2005) Autologous fascial sling vs. polypropylene tape at short term follow up: A prospective randomized study. J Urol 174(3): 990- 


\section{Open Access Journal of Urology \& Nephrology}

993.

2. Schauer I, Bock H, Eredics K, Wallis M, Scholz M, et al. (2017) 10 years follow-up after mid-urethral sling implantation: high rate of cure yet a re-occurrence of OAB-symptoms. Neurourol Urodyn 36(3): 614-619.

3. Costantini E, Kocjancic E, Lazzeri M, Giannantoni A, Zucchi A, et al. (2016) Long-term efficacy of the transobturator and retropubic mid-urethral slings for stress urinary incontinence: update from a randomized clinical trial. World J Urol 34(4): 585-593.

4. Clemons JL, Weinstein M, Guess MK, Alperin M, Moalli P, et al. AUGS Research Committee. (2013) Impact of the 2011 FDA transvaginal mesh safety update on AUGS members' use of synthetic mesh and biologic grafts in pelvic reconstructive surgery. Female Pelvic Med Reconstr Surg 19(4): 191-198.

5. Rac G, Younger A, Clemens JQ, Kobashi K, Khan A, et al. (2017) Stress urinary incontinence surgery trends in academic female pelvic medicine and reconstructive surgery urology practice in the setting of the food and drug administration public health notifications. Neurourol Urodyn 36(4): 1155-1160.

6. Tommaselli GA, Di Carlo C, Formisano C, Fabozzi A, Nappi C (2015) Medium-term and long-term outcomes following placement of midurethral slings for stress urinary incontinence: a systematic review and metaanalysis. Int Urogynecol J 26(9): 1253-1268.

7. Chou EC, Flisser AJ, Panagopopous G, Blaivas JG (2003) Effective treatment of mixed urinary incontinence with a pubovaginal sling. J Urol 170(2): 494-497.

8. Wadie BS, Mansour A, El-Hefnawy AS, Nabeeh A, Khair AA (2010) Minimum 2-year follow-up of mid-urethral slings, effect on quality of life, incontinence impact and sexual function. Int Urogynecol J 21(12): 1485-1490.

9. Baden WF, Walker TA, Lindsey JH (1968) The vaginal profile. Tex Med J 64(5): 56-58.

10. Krhut J, Zachoval R, Smith PP, Rosier PF, Valanský L, et al. (2014) Pad weight testing in the evaluation of urinary incontinence. Neurourol Urodyn 33(5): 507-510.

11. Figueiredo EM, Gontijo R, Vaz CT, Baracho E, da Fonseca AM, et al. (2012) The results of a 24-h pad test in Brazilian women. Int Urogynecol J 23(6): 785-789.

12. Erekson EA, Lopes VV, Raker CA, Sung VW (2010) Ambulatory procedures for female pelvic floor disorders in the United States. Am J Obstet Gynecol 2003(5): 497.
13. Foss Hansen M, Lose G, Kesmodel US, Gradel KO (2016) Reoperation for urinary incontinence: a nationwide cohort study. Am J Obstet Gynecol 214(2): 263.

14. Kim S, Harvey MA, Johnston S (2005) A review of the epidemiology and pathophysiology of pelvic floor dysfunction: Do racial differences matter?. J Obstet Gynaecol Can 27(3): 251-259.

15. Olen AL, Smith VJ, Bergstrom JO, Colling JC, Clark AL (1997) Epidemiology of surgically managed pelvic organ prolapse and urinary incontinence. Obstet Gynecol 89(4): 501-506.

16. Buchsbaum GM (2006) Urinary incontinence and pelvic organ prolapse. Minerva Urol Nefrol 58(4): 311-319.

17. Zeleke BM, Bell RJ, Billah B, Davis SR (2016) Symptomatic pelvic floor disorders in community-dwelling older Australian women. Maturitas 85: 34-41.

18. Cho MK, Kim CH, Kang WD, Kim JW, Kim SM, et al. (2012) Comparison of the clinical and quality-of-life outcomes after the inside-out TVT-0 procedure with or without concomitant transvaginal gynaecological surgery. J Obstet Gynaecol 32(3): 280-284.

19. Serati M, Braga A, Athanasiou S, Tommaselli GA, Caccia G, et al. (2017) Tension-free Vaginal Tape-Obturator for Treatment of Pure Urodynamic Stress Urinary Incontinence: Efficacy and Adverse Effects at 10-year Follow-up. Eur Urol 71(4): 674-679.

20. Richter HE, Albo ME, Zyczynski HM, Kenton K, Norton PA, et al. (2010) Urinary Incontinence Treatment Network: Retropubic versus transobturator midurethral slings for stress incontinence. N Engl J Med 362(22): 2066-2076.

21. Price DM, Noblett K (2012) Comparison of the cough stress test and 24-h pad test in the assessment of stress urinary incontinence. Int Urogynecol J 23(4): 429-433.

22. Jeon MJ, Jung HJ, Chung SM, Kim SK, Bai SW (2008) Comparison of the treatment outcome of pubovaginal sling, tension-free vaginal tape, and transobturator tape for stress urinary incontinence with intrinsic sphincter deficiency. Am J Obstet Gynecol 199(1): 76.

23. Ulrich D, Tammaa A, Hölbfer S, Trutnovsky G, BjelicRadisic V, et al. (2016) Ten-Year Follow-up after TensionFree Vaginal Tape-Obturator Procedure for Stress Urinary Incontinence. J Urol 196(4): 1201-1206.

24. Richter HE, Diokno A, Kenton K, Norton P, Albo M, et al. (2008) Predictors of treatment failure 24 months after surgery for stress urinary incontinence. J Urol 179(3): 1024-1030.

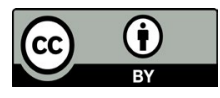

Bassem S Wadie, et al. Nine Year Median Follow Up of Mid-Urethral Slings and Autologous Sling, Single Center Experience. J Urol Nephrol 2020, 5(2): 000178. 